\title{
CANTERBURY PASTURES IN RELATION TO CROPPING AND SMALL SEEDS PRODUCTICN
}

By E. G. SMITH, Instructor in Agriculture, Department of Agriculture, Rangiora.

The area of Canterbury Plains and downlands capable of cultivation is about $2 \frac{8}{3}$ million acres.

Soils

Soil types on the plains vary from shallow light land soils to deep heavy loams and this range can occur within a relatively small area with the result that light, medium, and heavy soils may appear on one and the same farm or even within individual fields. The shallow and often stony light land soils and the medium loams predominate on the plains, though fairly extensive areas of friable, medium-heavy, to heavy loams are associated, in places, with the lighter types.

The downlands are typically medium to heavy silts and clays.

As a whole the soils of Canterbury respond well to lime and phosphate, but potash is generally adequate. Some are deficient in molybdenum and/or sulphur, while nitrogen may be used to advantage for such special purposes as the improvement of small seed yields.

\section{Climate}

The climate of the plains and downs is characterised by hot, dry summers and cold winters. Rainfall is fairly well distributed and ranges from about $25 \mathrm{in}$. per annum over most of the plains to nearly 50in. immediately west of the downs.

The temperature ranges from a mean of approximately 42 degrees F. in July to GO degrees in January, with up to 20 degrees of frost in winter and over 90 degrees F. in the shade in summer. The region has about 2000 hours of sunshine per annum.

Strong, hot nor'-west winds combined with low rainfall and high summer temperatures are a feature of the area, with the result that soil moisture normally falls to a low level in the summer and early autumn. 
Temperatures restrict the growing season to between early September and late April and moisture deficiencies are liable to prove a limiting factor at any time during the growing season.

\section{Farming Systems}

With their easy topography, amenable soils, and favourable spring and harvesting climate, it is not surprising that the plains and downlands of Canterbury have proved well suited to the growing and harvesting of cereal and small seed crops in association with the production of wool and fat lambs under mixed farming systems.

Nevertheless, during 100 years of settlement, the relationship between crops, pastures, and livestock has undergone several significant changes.

It is not possible in a paper such as this to trace the causes and repercussions of these changes. However, it is of interest to note that, from an extensive form of livestock farming in the early days of settlement, .Canterbury in the late 1870's and early 1880's entered a cropping phase when the growing of cereals on a large scale was a feature. For instance, in 1883, 400,000 . acres of cereal crops were threshed in Canterbury.

Today mixed farming prevails, but the emphasis has shifted from "cash" cropping to pastures and grassland products. This swing from annual crops to pastures has been brought about mainly by the greater use of lime and phosphates, the 'availability of more highly productive and persistent "strains" of pasture plants, and the relatively higher returns from fat lambs, wool, and small seeds.

In the early days cereal crops followed cereal crops for several consecutive years in the same field. Cultivation was often haphazard and lime and fertiliser were not used. Hence the original fertility of the soil was soon depleted and yields per acre declined.

This drain on soil fertility under a one crop system was checked to some extent in the early 1890's when the fat lamb trade was established commercially and the rape crop was brought into the rotation. Even then, grazing was only secondary to cropping and pastures were invariably sown down with cereals or supplementary feed crops, and only when the land was no longer sufficiently fertile for cash cropping.

\section{"Strain" in Pasture Plants}

The value of strain in pasture plants was unknown, clovers were seldom included in the mixtures, and even 
when they were included they often failed to establish because the condition of the soil was not suitable for their growth.

Italian and perennial ryegrasses formed the bulk of the pasture mixture and as a result of cross pollination and the fact that ryegrass seed crops were usually harvested in the first year, the short-lived species soon became dominant and formed the parents of subsequent seed crops. Areas sown with this seed failed to produce much feed after the second year or to persist for any length of time.

\section{Changing Pattern.}

It was not until some 20 years ago that pasture became the most important crop. Trials laid down by the Department of Agriculture had demonstrated the value of heavy applications of lime and regular topdressing with phosphates to stimulate vigorous clover growth. The development of improved strains of pasture plants by the Grasslands Division of the Department of Scientific and Industrial Research and the subsequent introduction of seed certification in the early 1930 's gave farmers an appreciation of the importance of "strain" in pasture plants and the value of grass as a crop.

An improvement in economic conditions after the mid 1930's encouraged the wider use of lime, phosphate, and certified seed. Stock carrying capacity and soil fertility were improved and so the pattern of farming gradually changed from one of short-lived pastures and over-cropping, to one where cereal crops are ' now grown on only a limited area and in a rotation planned largely to pave the way for long-term pasture renewal.

Attractive prices for certified seeds did much to popularise the sowing and seeding of these superior strains and for some time the majority of farmers sowed certified seeds only on paddocks intended for seed production. However, it was not long before these areas proved their worth for grazing and where, previously, pastures had grown little after the first 2 or 3 years, their productive life was now doubled. Over this 20 year period the area in annual cash crops has dropped from 390,000 acres to 140,000 acres. The area topdressed' with lime and fertiliser has increased from 73,000 acres to 740,000 acres and- the number of sheep shorn has risen by nearly $1 \frac{3}{4}$ million. 


\section{Crop Rotation}

There is still no fixed rotation practised, but the general trend is to permit a summer fallow before sowing down to grass. A common rotation is out of old grass to rape; then wheat or barley ; followed by a greenfeed cereal and summer fallow before regrassing in autumn.

The old pasture is winter ploughed and sown to rape during spring, lambs are fattened on the rape crop, and ewes flushed on the second growth before the area is ploughed for winter wheat or spring barley. In short, soil fertility built up during the period in grass and forage crop is turned into cash through the cereal and fertility is again improved by grazing of the greenfeed and the benefits of summer fallow.

Although it is generally agreed that autumn sowing after a summer fallow is most reliable, spring sowing of pasture with a cover crop such as rape is still a common practice and many really high-class pastures are established in this way.

On farms where cereal cropping is not practised a popular rotation is from old pasture to turnips followed by rape and grass.

The old pasture is winter ploughed and fallowed, usually until midsummer, when turnips are sown for wintering sheep. The turnip shells remaining after the initial grazing are grubbed for a final feeding and the land is then worked in early spring in preparation for sowing down to rape and grass in OctoberNovember.

\section{Seed Mixtures}

Seed mixtures vary with conditions, but many of those sown today are designed for seed production as well as for grazing. The most favoured permanent pasture mixture is the simple one of perennial ryegrass and white clover. Simple mixtures are also used for temporary pastures, the most popular being shortrotation ryegrass with cowgrass, and/or white clover.

Complex mixtures are not widely used, although cocksfoot is gaining favour on light to medium land, timothy is frequently included for heavy soils, and crested dogstail is used in many mixtures.

The general trend is towards lighter seedings, but there is still a greater diversity of opinion regarding optimum rates. Many farmers still sow up to $401 \mathrm{~b}$ of perennial ryegrass with $51 \mathrm{~b}$ of white clover per acre, while others sow less than half these quantities, Each 
school of thought can quote examples to prove superiority of its practice.

The rate of seeding most commonly used for permanent pasture is $20 \mathrm{lb}$ of perennial ryegrass with $2-31 b$ of "white clover and for temporary pasture $25-301 \mathrm{lb}$ of short-rotation ryegrass with 2-31b of white clover or $3 \mathrm{lb}$ of cowgrass and $2 \mathrm{lb}$ of white clover.

If cocksfoot is to make a worthwhile contribution to the mixed sward, only a light seeding of ryegrass, preferably perennial ryegrass, should be used, while the seeding of cocksfoot should be proportionately high. Not more than 10lb of ryegrass and not less than $61 \mathrm{~b}$ of cocksfoot with suitable clovers is recommended. Even then grazing should be lenient until the cocksfoot plants are well established and one of the most practicable methods of ensuring good cocksfoot establishment in a mixed sward is to close the area for a ryegrass seed crop in the first year.

The same principles apply when establishing timothy in a mixed sward. A mixture of $8-10 \mathrm{lb}$ of either short-rotation or perennial ryegrass with 5-6lb of timothy together with the usual clovers will give good results.

\section{Methods of Sowing}

Methods of sowing vary from season to season and from farm to farm. In dry autumns or in spring when unfavourable weather is likely to follow sowing, drilling is safest, for the seed is thereby placed in moist soil at an even depth and the fertiliser is concentrated with the seed. Drilling is gaining in popularity since the introduction of various drill modifications to the standard coulter, these give a better spread of seed and thereby either eliminate or at least quickly reduce the space between drills.

Under more favourable conditions broadcasting is ideal. Some farmers remove coulters and tubes from' the grain drill and broadcast seed and fertiliser directly after the Cambridge roller. By rolling, broadcasting, and harrowing in one operation, soil moisture is brought to the surface and corrugations left by the roller act as drills. When the seedlings make their - appearance one gains the impression that the seed has been sown in drills about one inch apart. The roller drill combination as used when sowing down to pasture on an extensive scale in the pumice areas of the North Island gives similar results.

The use of lime and superphosphate has become standard practice in pasture establishment. From 1-2 
tons of lime and 1-Zcwt of superphosphate, depending on soil requirements is normally applied at time of sowing,

\section{Grazing $M$ anagement}

Careful management of the establishing sward is of the utmost importance and in its early life quick grazing with a heavy concentration of sheep is desirable; 30-40 sheep per acre or even more for a few days may be necessary. Subsequent management must be made to fit stock requirements and any system of pasture management should aim at maximum production of meat and wool and, where applicable; small seeds.

It is impracticable to discuss pasture and crop management on the mixed farms of Canterbury without considering the feed requirements of ewes and lambs.

The growing season of pastures has been extended by the wider use of lucerne-grass mixtures, by the general practice of sowing improved strains of other pasture plants, by applications of lime, phosphates, and sometimes, artificial nitrogen. The use of D.D.T. for the control of grass-grub and porina has taken some of the "ifs" out of pasture establishment and maintenance. Yet the relationship between pasture and the animals that eat it is not widely understood and therefore much of the grass growth is still not utilised to the best advantage.

Wastage frequently occurs owing to late weaning of lambs and again when ewes are allowed more than a maintenance ration between weaning and flushing and between flushing and mid-winter.

Directly after weaning breeding ewes should be concentrated on paddocks to be winter ploughed and where necessary threshed ryegrass straw or poorest , quality hay may be fed. This practice not only holds ewes in good store condition, but also results in raising soil fertility on the area to be cropped and allows better pastures to be spelled.

\section{Surplus Growth}

Canterbury pastures make more than half their annual growth during October, November, and December. It is impossible to stock to the capacity of these months and therefore surplus growth must be saved in the form of hay, silage; or small seeds and seed straw to achieve efficient utilisation of herbage production. In districts suitable for its growth the area in lucerne 
has increased very substantially in recent years and on many properties lucerne now meets all hay requirements.

Although farmers have a growing appreciation of the value of silage, a relatively small proportion of the spring a.nd early summer surplus is ensiled. Early cuts of silage keep growth under control, ensure good aftermath for lambs after weaning, and provide useful fodder reserves for times of shortage.

\section{S mall Seeds}

On many properties small seed production is now an integral part of the farm programme. First year paddocks are generally saved for ryegrass seed crops. Such swards are relatively weed-free and because of their initial vigour give maximum seed yields. White or red clover may be harvested from second year stands without materially affecting the future productive life of the pasture for grazing purposes.

Baling of seed straw removes a potential harbour for slugs and grass grub and provides autumn and early winter feed for sheep and cattle.

The optimum time for closing areas for small seeds, hay, or silage coincides with the period of maximum spring growth and all growth surplus to stock requirements should be saved in one form or another for use in less favourable seasons.

Pasture growth fails to meet stock requirements at two main periods (1) midsummer and (2) winter and early spring.

For the midsummer period rape is the popular choice of fattening crop for topping off those lambs that fail to make the grade off the mothers while seed straw or poorest quality hay may be fed to ewes after weaning.

The winter gap is bridged by feeding seed straw, hay, silage, and supplementary fodder crops such as turnips, chou moellier, greenfeed cereals, while autumn-saved pasture is nursed for early spring grazing.

These two major gaps in seasonal feed requirements can be substantially reduced by better pasture utilisation.

\section{Conclusion}

Over the last 20 years grass has become the most important crop in Canterbury, but in periods of prolific growth is wasted. The significant relationship between cereal crops, high-producing pasture, and the grazing animal is not widely appreciated. Soil fertil- 
ity is at its peak when pasture is at its best and on land suitable for cropping, fertility should be cashed at that time by growing a cereal crop. Areas to -be taken out of grass for crop should be heavily stocked after weaning to give a further build-up in plant food before winter ploughing. This system fits in well with good flock management, ensures heavier crop yields, and allows other pastures to be spelled for later grazing.

Present prices for farm produce encourage land owners to concentrate on livestock products and small seed production and to neglect cereal cropping. Therefore pastures are allowed to deteriorate before ploughinp. While these conditions obtain neither cereal crop yields nor stock carrying capacity will reach their potential on the plains and downlands of Canterbury.

\section{DISCUSSION}

Q. Are New Zealand farmers content with the palatability of ryegrass as compared to cocksfoot and timothy?

A. No, the farmers of Canterbury are not perfectly happy about anything. We find over most of Canterbury no other grass will perform so well as perennial ryegrass will do. A farmer told me over twenty years ago he would not have been on his farm if it were not for perennial ryegrass, which farmers at that time condemned. If you hold the balance between clover and ryegrass it is reasonably palatable. If stock have a choice between short-rotation and perennial they prefer the quicker growing grass. Generally speaking here there is a little unpalatability in perennial ryegrass. It is difficult to hold timothy in most swards where sheep graze. Cocksfoot is being used quite a lot on light to medium soils, but annual production is lower than that of perennial ryegrass.

Q. Are you talking about bulk of dry matter produced per acre or fat-lamb produced per acre ? Timothy as a single crop in the south out-produces perennial ryegrass in iamb meat produced per acre but perhaps not in dry matter.

A. I referred to lamb meat and wool per acre. Timothy we do know is very palatable and is generally eaten out of our pastures by mismanagement. Timothy is best sown with clovers as a special purpose pasture. We can manage it more easily this way. 